\title{
ESCRITA CIENTÍFICA DE ALUNOS DE GRADUAÇÃO EM QUÍMICA: ANÁLISE DE RELATÓRIOS DE LABORATÓRIO
}

\author{
Jane Raquel Silva de Oliveira e Alzir Azevedo Batista \\ Departamento de Química, Universidade Federal de São Carlos, Rod. Washington Luiz, km 235, 13565-905 São Carlos - SP, Brasil \\ Salete Linhares Queiroz* \\ Instituto de Química de São Carlos, Universidade de São Paulo, CP 780, 13560-970 São Carlos - SP, Brasil
}

Recebido em 22/9/09; aceito em 17/5/10, publicado na web em 21/9/10

\begin{abstract}
UNDERGRADUATE CHEMISTRY STUDENTS' SCIENTIFIC WRITING: ANALYSIS OF LABORATORY REPORTS. The purpose of this study was to analyze written arguments found within laboratory reports by undergraduate students in a practical inorganic chemistry course. The quality of students' argumentation was analyzed based on the argumentation model developed by Kelly and Takao. Students presented scientific arguments grounded in data and building toward theoretical assertions. This indicates that students have some understanding of the rhetorical power of data in their explanations. The findings of this study also support the idea that Kelly and Takao's model is effective in other disciplines and in other rhetorical tasks distinct from those originally analyzed by them in their domain of oceanography.
\end{abstract}

Keywords: chemistry; laboratory reports; argumentation.

\section{INTRODUÇÃO}

Nas últimas décadas pesquisadores da área de educação em ciências de vários países têm destacado a apropriação da linguagem científica como elemento essencial, tanto para a prática da ciência, quanto para seu aprendizado. ${ }^{1}$ Lemke, ${ }^{2}$ dentre outros pesquisadores, ${ }^{3-5}$ entende que aprender ciência significa se apropriar do discurso da ciência; significa, dentre outras coisas, descrever, comparar, classificar, analisar, discutir, teorizar, concluir, generalizar; significa, portanto, compreender a linguagem empregada pela comunidade científica. Sob esta perspectiva vem ocorrendo em vários países uma crescente conscientização a respeito da necessidade de tal apropriação por parte dos alunos.

As atuais orientações curriculares para o ensino superior de Química no nosso país também colocam em pauta a importância de se contemplar na formação dos graduandos o desenvolvimento de competências e habilidades relacionadas à linguagem científica. Esse aspecto pode ser notado nas Diretrizes Curriculares Nacionais para os Cursos de Química ${ }^{6}$ que apontam para a necessidade dos estudantes aprenderem não somente "os conceitos, leis e princípios da química", mas também a "ler, compreender e interpretar os textos científico-tecnológicos", "escrever, apresentar e defender seus achados" "saber comunicar corretamente os projetos e resultados de pesquisa na linguagem científica", dentre outras.

Apesar dessas recomendações o que se observa, no entanto, são as frequentes menções na literatura sobre a flagrante dificuldade encontrada pelos estudantes na comunicação de seus conhecimentos, assim como na leitura e interpretação de textos científicos. ${ }^{7,8}$ De fato, em estudo anterior, ${ }^{9}$ no qual buscamos conhecer as concepções de graduandos, pós-graduandos e de um professor do ensino superior de Química em relação à comunicação científica, percebemos um consenso sobre a importância da apropriação da linguagem científica para a formação do químico. Em contraponto foram também destacadas as dificuldades que os alunos enfrentam quando necessitam se expressar em linguagem científica.

Verificamos, por exemplo, que os graduandos desejam o oferecimento de mais oportunidades ao longo do curso nas quais possam

*e-mail: salete@iqsc.usp.br desenvolver suas habilidades relacionadas à comunicação científica, o que de certa forma evidencia suas dificuldades neste campo. Além disso, pós-graduandos revelaram que, em geral, os relatórios de pesquisa elaborados no grupo em que atuam são semelhantes, pois os novatos, devido às dificuldades que têm na produção de textos científicos, simplesmente "olham" como os outros membros do grupo elaboram os trabalhos e procuram imitá-los. Por fim, ainda no contexto de discussão sobre os relatórios de laboratórios, o professor destacou que, na maioria das vezes, nem os próprios docentes recebem durante sua formação orientações precisas a respeito da elaboração de textos científicos, que aprendem "aos trancos e barrancos" e, assim, vão repassando aos seus alunos a maneira como eles consideram mais correta. ${ }^{9}$

Os relatos mencionados ratificam a necessidade do desenvolvimento de trabalhos que forneçam subsídios tanto aos alunos quanto aos professores no que tange, respectivamente, à elaboração e análise da qualidade dos textos científicos produzidos nos ambientes de ensino, como, por exemplo, os relatórios de laboratório. ${ }^{10}$ Embora na literatura internacional existam diversos trabalhos produzidos no sentido de aprimorar a escrita científica de estudantes do ensino superior e habilitá-los na elaboração de textos científicos, ${ }^{11}$ o mesmo não ocorre no âmbito nacional. Assim, localizamos um único trabalho na seção Educação desta revista, no intervalo de 1998 a 2009, que relata estratégias aplicadas em uma disciplina experimental do ensino superior - Química Geral Experimental, oferecida pela Universidade Federal do Piauí - com o objetivo de orientar os alunos na elaboração de relatórios de laboratório. ${ }^{12}$

Alguns poucos autores, ${ }^{13}$ visando auxiliar os alunos no aprimoramento da linguagem científica e fornecer subsídios aos professores para a avaliação da qualidade dos textos por eles produzidos, propõem modelos para avaliação da escrita científica, que consideram tanto aspectos estruturais quanto a maneira como dados e teoria são apresentados e correlacionados. Um desses modelos, proposto por Kelly e Takao ${ }^{14}$ e denominado Modelo de Argumentação, procura relacionar a quantidade e a natureza das informações presentes nos textos produzidos pelos alunos no cumprimento de determinadas tarefas de uma disciplina de Oceanografia com a maneira como tais informações são articuladas de forma a construir argumentos fortes. 
O modelo fornece, portanto, critérios e elementos que permitem avaliar os textos dos estudantes, levando em consideração a maneira como apresentam e articulam as informações teóricas, específicas ou não da área em questão, e os dados obtidos experimentalmente.

Neste trabalho tivemos como objetivo investigar a qualidade da escrita científica de estudantes de graduação em Química, tomando como objeto de estudo relatórios de laboratório produzidos no contexto de uma disciplina experimental da área de Química Inorgânica. Para tanto, adaptamos o Modelo de Argumentação de Kelly e Takao ${ }^{14}$ e o utilizamos na análise de tais textos.

\section{CONTEXTO DA PESQUISA}

Este estudo foi realizado em uma disciplina experimental da área de Química Inorgânica oferecida no $7^{\circ}$ semestre de um curso de Bacharelado em Química de uma universidade pública paulista. No primeiro semestre de 2008, essa contava com 18 alunos matriculados, sendo 11 do sexo feminino e 7 do sexo masculino. Nas aulas, realizadas uma vez por semana durante $4 \mathrm{~h}$, os alunos trabalharam em grupos, sendo 6 grupos formados por 2 alunos, e 2 grupos por 3 alunos.

As atividades da disciplina envolveram: introdução de técnicas de síntese e caracterização de compostos de coordenação, em particular de compostos de cobalto; produção de relatórios; apresentação de seminários.

Para a realização das atividades de síntese e caracterização dos compostos de coordenação não foram fornecidos roteiros de aula prática, como tradicionalmente ocorre nas disciplinas experimentais. No primeiro dia de aula os alunos receberam uma lista com as referências bibliográficas dos livros nos quais estavam descritos os experimentos que seriam executados. Esse material bibliográfico foi localizado pelos alunos e os procedimentos para os experimentos foram estudados pelos mesmos antes do dia da aula. Dessa forma, os próprios alunos elaboravam um esboço ou resumo das etapas a serem realizadas no dia da aula. Esse procedimento foi adotado com o intuito de estimular os alunos a realizar pesquisas bibliográficas e estudar previamente as atividades experimentais. O Quadro 1 lista os experimentos realizados durante o semestre letivo e as respectivas referências bibliográficas.

Os alunos realizaram três conjuntos de experimentos: o primeiro foi relacionado à síntese e caracterização do composto cloreto de tris(etilenodiamina)cobalto(III), $\left[\mathrm{Co}\left(\mathrm{C}_{2} \mathrm{H}_{8} \mathrm{~N}_{2}\right)_{3}\right] \mathrm{Cl}_{3}$; o segundo envolveu a síntese e caracterização do composto cloreto de penta-aminclorocobalto(III), $\left[\mathrm{Co}\left(\mathrm{NH}_{3}\right)_{5} \mathrm{Cl}_{3} \mathrm{Cl}_{2}\right.$, o qual serviu de precursor para a síntese e caracterização dos isômeros cloreto de penta-aminonitrocobalto(III), $\left[\mathrm{Co}\left(\mathrm{NH}_{3}\right)_{5}\left(\mathrm{NO}_{2}\right)\right] \mathrm{Cl}_{2}$, e cloreto de penta-aminonitritocobalto(III), $\left[\mathrm{Co}\left(\mathrm{NH}_{3}\right)_{5}(\mathrm{ONO})\right] \mathrm{Cl}_{2}$; o terceiro conjunto de experimentos envolveu a síntese e caracterização do oxalato de hexamincobalto(III), $\left[\mathrm{Co}\left(\mathrm{NH}_{3}\right)_{6}\right]_{2}\left(\mathrm{C}_{2} \mathrm{O}_{4}\right)_{3}$. Em geral, cada um desses compostos foi sintetizado em uma aula e caracterizado na aula seguinte. As técnicas empregadas para a caracterização de todos os compostos foram: espectroscopia vibracional na região do IV, espectroscopia eletrônica na região do UV-Visível, medida de condutividade eletrolítica, susceptibilidade magnética e medida do ponto de fusão.

Com relação à produção de relatórios de laboratório, estes deveriam apresentar as seguintes seções: Introdução, Materiais e Métodos (Parte Experimental), Resultados e Discussão, Conclusões e Referências Bibliográficas. Para auxiliar os alunos na elaboração dos relatórios, produzimos o material didático "Estrutura de Relatórios de Laboratório" (disponível como Material Suplementar), baseado no livro "Comunicação e linguagem científica: guia para estudantes de Química" ${ }^{15}$ contendo informações básicas sobre aspectos estruturais dos mesmos. O material foi dividido da seguinte forma: Parte 1: As principais seções do relatório de laboratório; Parte 2: Citações e referências bibliográficas; Parte 3: Características da seção "Introdução"; Parte 4: "Materiais e Métodos" - importância e características; Parte 5: Gráficos, tabelas e figuras - cuidados importantes; Parte 6: Discussão dos "Resultados e Conclusões". Assim, geralmente no início da cada aula, o material didático referente a cada um dos tópicos foi entregue aos alunos e seu conteúdo discutido com a turma.

O material didático foi produzido com o intuito de apresentar e discutir questões relevantes que devem ser consideradas na produção de relatórios de laboratório e que favorecem a produção de uma escrita científica de qualidade. Nos anos anteriores, instruções dessa natureza já eram oferecidas de maneira pulverizada ao longo da disciplina pelo professor responsável. Assim, o material não foi idealizado tendo em vista a aplicação de estratégias ou ações direcionadas especificamente ao auxílio dos alunos no processo de argumentação, não sendo, portanto, viável levantar hipóteses sobre a influência do seu uso na argumentação por eles apresentada nos relatórios. Nesse mesmo sentido, esclarecemos que o Modelo de Argumentação de Kelly e Takao ${ }^{14}$ também não foi apresentado aos alunos, tendo sido utilizado apenas para subsidiar a análise da qualidade da escrita científica. Em outras palavras, a disciplina foi conduzida de forma semelhante a muitas outras de caráter experimental existentes nas universidades brasileiras.

Durante o semestre, cada grupo produziu quatro relatórios: o primeiro, sobre a atividade de síntese e caracterização do composto $\left[\mathrm{Co}\left(\mathrm{C}_{2} \mathrm{H}_{8} \mathrm{~N}_{2}\right)_{3}\right] \mathrm{Cl}_{3}$; o segundo, relacionado ao composto $\left[\mathrm{Co}\left(\mathrm{NH}_{3}\right)_{5} \mathrm{Cl}\right]$ $\mathrm{Cl}_{2}$; o terceiro abordando comparativamente a síntese e caracterização dos isômeros $\left[\mathrm{Co}\left(\mathrm{NH}_{3}\right)_{5}\left(\mathrm{NO}_{2}\right)\right] \mathrm{Cl}_{2}$ e $\left[\mathrm{Co}\left(\mathrm{NH}_{3}\right)_{5}(\mathrm{ONO})\right] \mathrm{Cl}_{2}$; e um relatório final que, além de apresentar a análise da síntese do composto $\left[\mathrm{Co}\left(\mathrm{NH}_{3}\right)_{6}\right]_{2}\left(\mathrm{C}_{2} \mathrm{O}_{4}\right)_{3}$, deveria também comparar e discutir a síntese e caracterização de todos os demais.

Por fim, com o intuito de criar um espaço para discussão e comparação dos resultados obtidos por cada um dos grupos nos experimentos propostos, bem como esclarecer dúvidas sobre os compostos sintetizados, o professor solicitou que os alunos apresentassem dois seminários sobre os experimentos realizados no semestre. No primeiro seminário os grupos apresentaram os resultados obtidos nos experimentos de síntese e caracterização dos compostos $\left[\mathrm{Co}\left(\mathrm{C}_{2} \mathrm{H}_{8} \mathrm{~N}_{2}\right)_{3}\right]$

Quadro 1. Experimentos realizados durante o semestre na disciplina experimental da área de Química Inorgânica

\begin{tabular}{|c|c|c|}
\hline & Referência do experimento & Composto sintetizado e caracterizado \\
\hline $\begin{array}{l}1^{\mathrm{o}} \text { conjunto de } \\
\text { experimentos }\end{array}$ & $\begin{array}{l}\text { BOOTH, H. S. Inorganic Syntheses. vol II. New York: McGraw-Hill } \\
\text { Book Company, 1939. p. 221-222. }\end{array}$ & Cloreto de tris(etilenodiamina)cobalto(III) $-\left[\mathrm{Co}\left(\mathrm{C}_{2} \mathrm{H}_{8} \mathrm{~N}_{2}\right)_{3}\right] \mathrm{Cl}_{3}$ \\
\hline $\begin{array}{l}2^{\circ} \text { conjunto de } \\
\text { experimentos }\end{array}$ & $\begin{array}{l}\text { WOOLLINS, J. D. (Ed). Inorganic Experiments. } 1^{\text {st }} \text { ed New York: } \\
\qquad \text { VCH, 1994. p.26. }\end{array}$ & $\begin{array}{l}\text { Cloreto de penta-aminclorocobalto(III) }-\left[\mathrm{Co}\left(\mathrm{NH}_{3}\right)_{5} \mathrm{Cl}\right] \mathrm{Cl}_{2} \\
\text { Cloreto de penta-aminonitrocobalto(III) }-\left[\mathrm{Co}\left(\mathrm{NH}_{3}\right)_{5}\left(\mathrm{NO}_{2}\right)\right] \mathrm{Cl}_{2} \text { (isômero I) } \\
\text { Cloreto de penta-aminonitritocobalto(III) }-\left[\mathrm{Co}\left(\mathrm{NH}_{3}\right)_{5}(\mathrm{ONO})\right] \mathrm{Cl}_{2} \text { (isômero II) }\end{array}$ \\
\hline $\begin{array}{l}3^{\circ} \text { conjunto de } \\
\text { experimentos }\end{array}$ & $\begin{array}{c}\text { BOOTH, H. S (Ed.). Inorganic Syntheses. vol II. New York: } \\
\text { McGraw-Hill, 1939. p. } 220 .\end{array}$ & Oxalato de hexamincobalto (III) $-\left[\mathrm{Co}\left(\mathrm{NH}_{3}\right)_{6}\right]_{2}\left(\mathrm{C}_{2} \mathrm{O}_{4}\right)_{3}$ \\
\hline
\end{tabular}


$\mathrm{Cl}_{3}$ e $\left[\mathrm{Co}\left(\mathrm{NH}_{3}\right)_{5} \mathrm{Cl}\right] \mathrm{Cl}_{2}$, enquanto no segundo, relataram, comparativamente, a síntese e caracterização dos isômeros $\left[\mathrm{Co}\left(\mathrm{NH}_{3}\right)_{5}\left(\mathrm{NO}_{2}\right)\right]$ $\mathrm{Cl}_{2}$ e $\left[\mathrm{Co}\left(\mathrm{NH}_{3}\right)_{5}(\mathrm{ONO})\right] \mathrm{Cl}_{2}$, bem como a síntese e caracterização do composto $\left[\mathrm{Co}\left(\mathrm{NH}_{3}\right)_{6}\right]_{2}\left(\mathrm{C}_{2} \mathrm{O}_{4}\right)_{3}$.

\section{PERCURSO METODOLÓGICO}

\section{Modelo de argumentação de Kelly e Takao}

Para a análise da qualidade da escrita científica dos relatórios de laboratórios, adotamos o modelo proposto por Kelly e Takao, ${ }^{14}$ descrito sucintamente a seguir.

Kelly e Takao ${ }^{14}$ partem do princípio que o Modelo de Argumentação de Toulmin, ${ }^{16}$ frequentemente usado por pesquisadores da área de educação em ciências, ${ }^{13,17,18}$ permite a reflexão sobre a estrutura do argumento e ajuda a evidenciar seus componentes, destacando a importância das relações lógicas que devem haver entre eles. No entanto, chamam a atenção para o fato do Modelo não conduzir a julgamentos sobre a verdade ou adequação do argumento e apresentar a argumentação sem levar em consideração o contexto no qual o argumento é produzido. Assim, consideram que os argumentos devem ser analisados não somente do ponto de vista estrutural, mas também do ponto de vista epistêmico, e que em contextos nos quais argumentações escritas longas são produzidas, é necessário considerar os aspectos interacionais dos argumentos nelas apresentados.

Nesta perspectiva, os autores desenvolveram um modelo no qual o analista precisa capturar operações com as quais os participantes trazem para os discursos informações relevantes ao domínio do conhecimento específico (conceitos, definições etc) e implementam procedimentos e modos de raciocínio típicos deste campo de conhecimento, conferindo status epistêmico às conclusões estabelecidas. Uma vez identificadas tais operações, faz-se necessário observar se estas se encontram no contexto de um discurso argumentativo. Em caso afirmativo os argumentos presentes no discurso são classificados em níveis epistêmicos. A qualidade do texto científico será, dessa forma, determinada a partir da distribuição das sentenças que formam o argumento nos diversos níveis epistêmicos e, também, a partir das relações existentes entre os argumentos dispostos nos diversos níveis epistêmicos.

No que diz respeito aos níveis epistêmicos Kelly e Takao ${ }^{14}$ sugeriram o estabelecimento de seis níveis que foram organizados com base, principalmente, em considerações feitas por Bruno Latour ${ }^{19}$ sobre as características da escrita científica. Segundo esse autor, na produção dos seus argumentos os cientistas realizam movimentos retóricos que se iniciam com a apresentação das contingências atuais dos seus experimentos (proposições muito específicas) até alcançarem o estabelecimento de generalizações.

A Tabela 1 indica a definição dada pelos autores para cada um dos níveis em um trabalho que tratou de conteúdos específicos da área de Oceanografia. ${ }^{14}$ Com base nessas definições, para a realização da nossa análise, os níveis foram redefinidos de acordo com os conteúdos específicos da área de Química Inorgânica (subárea Química de Coordenação) e encontram-se descritos na Tabela 2.

\section{Coleta e análise dos dados}

Para a análise realizada nesta pesquisa, selecionamos os relatórios finais produzidos pelos estudantes, uma vez que nesses textos eles deveriam apresentar e discutir comparativamente os resultados obtidos em todas as atividades de síntese e caracterização dos compostos, o que exigiria uma maior capacidade de articulação entre os dados experimentais e os fundamentos teóricos para a elaboração de argumentos científicos. Cabe destacar que apenas 5 grupos
Tabela 1. Níveis epistêmicos estabelecidos por Kelly e Takao ${ }^{14}$ para a análise de argumentos produzidos por estudantes de uma disciplina de Oceanografia

\begin{tabular}{lc}
\hline $\begin{array}{l}\text { Nível } \\
\text { Epistêmico }\end{array}$ & Definição \\
\hline VI & $\begin{array}{c}\text { Proposições gerais que reportam processos geológicos e fazem } \\
\text { referência a definições usualmente presentes em livros-texto. } \\
\text { O conhecimento apresentado pode ser mais amplo, não apenas } \\
\text { relacionado à área geográfica em estudo. }\end{array}$ \\
V & $\begin{array}{c}\text { Proposições apresentadas na forma de assertivas teóricas ou de } \\
\text { modelos específicos para a área geográfica em estudo. }\end{array}$ \\
IV & $\begin{array}{c}\text { Proposições apresentadas na forma de assertivas teóricas ou } \\
\text { de modelos que são ilustrados com dados específicos da área } \\
\text { geográfica em estudo. }\end{array}$ \\
III & $\begin{array}{c}\text { Proposições que descrevem relações entre as estruturas ge- } \\
\text { ológicas específicas da área geográfica em estudo. }\end{array}$ \\
II & $\begin{array}{c}\text { Proposições que identificam e descrevem propriedades e } \\
\text { características topográficas da estrutura geológica específica } \\
\text { da área geográfica em estudo. }\end{array}$ \\
I & $\begin{array}{c}\text { Proposições que fazem referência explícita à representação de } \\
\text { dados (em gráficos, tabelas etc). }\end{array}$ \\
\hline
\end{tabular}

Tabela 2. Níveis epistêmicos para a análise de argumentos produzidos por estudantes de uma disciplina de Química Inorgânica (sub-área Química de Coordenação), adaptados do modelo de Kelly e Takao ${ }^{14}$

\begin{tabular}{lc}
\hline $\begin{array}{l}\text { Nível } \\
\text { Epistêmico }\end{array}$ & Definição \\
\hline VI & $\begin{array}{c}\text { Proposições gerais que fazem referência a definições e a con- } \\
\text { ceitos usualmente presentes em livros-texto. O conhecimento } \\
\text { apresentado pode ser mais amplo, não apenas relacionado à } \\
\text { área de Química de Coordenação. }\end{array}$ \\
V & $\begin{array}{c}\text { Proposições apresentadas na forma de assertivas teóricas ou de } \\
\text { modelos específicos para área de Química de Coordenação. }\end{array}$ \\
IV & $\begin{array}{c}\text { Proposições apresentadas na forma de assertivas teóricas ou } \\
\text { de modelos ilustrados com dados específicos para a área de } \\
\text { Química de Coordenação. }\end{array}$ \\
III & $\begin{array}{c}\text { Proposições que descrevem relações entre as propriedades e } \\
\text { as características de compostos de coordenação baseadas em } \\
\text { representações de dados. }\end{array}$ \\
II & $\begin{array}{c}\text { Proposições que identificam e descrevem propriedades e } \\
\text { características de compostos de coordenação baseadas em } \\
\text { representações de dados. }\end{array}$ \\
I & $\begin{array}{c}\text { Proposições que fazem referência explícita à representação de } \\
\text { dados (em gráficos, tabelas etc). }\end{array}$ \\
\hline
\end{tabular}

cumpriram tal exigência, os outros 3 apresentaram no relatório final apenas discussões referentes ao último composto sintetizado. Assim, analisamos neste trabalho os 5 relatórios finais que apresentaram os dados obtidos em todos os experimentos.

Em cada relatório selecionado analisamos as proposições presentes na seção Resultados e Discussão, uma vez que a maior parte das sentenças argumentativas foi apresentada nessa seção. Tomamos como unidade de análise cada período presente nos textos dos alunos, ou seja, proposição contendo uma ou mais orações e encerrada por ponto final. Cada uma das unidades de análise recebeu um número, foi digitada em uma tabela e então classificada em níveis epistêmicos de acordo com as definições descritas na Tabela 2. Essa classificação foi realizada primeiramente pelo Analista 1 (terceiro autor) e depois conferida pelo Analista 2 (segundo autor). Todos os casos nos quais existiram discordâncias quanto à classificação das proposições foram colaborativamente revistos até o alcance de um consenso entre os analistas. 
Cabe ainda destacar que, dependendo da natureza dos argumentos presentes nos relatórios, uma mesma proposição podia ser classificada em mais de um nível epistêmico e que afirmações que não se encaixavam em nenhum dos níveis epistêmicos, que usualmente forneciam apenas informações sobre condições nas quais os experimentos haviam sido realizados, foram classificadas como N.A. (não se aplica).

\section{RESULTADOS E DISCUSSÃO}

Analisamos neste trabalho a escrita científica de estudantes de graduação em Química a partir do Modelo de Kelly e Takao. ${ }^{14}$ Como descrito anteriormente, as proposições presentes na seção Resultados e Discussão dos relatórios foram classificadas de acordo com níveis epistêmicos definidos na Tabela 2.

Na Tabela 3 apresentamos os argumentos elaborados pelos alunos em um dos relatórios e a maneira como as proposições foram analisadas de acordo com os níveis epistêmicos. Tais proposições foram transcritas neste trabalho respeitando-se totalmente suas características originais. Os demais relatórios foram analisados similarmente.

Em algumas proposições foi possível identificar mais de um nível epistêmico, revelando a presença de argumentos nos quais os alunos foram capazes, por exemplo, de apresentar dados, estabelecer comparações entre eles e fazer afirmações teóricas. Esses casos demonstram que através do Modelo em questão é possível realizar a análise de argumentações longas, considerando os aspectos interacionais que existem entre os argumentos. Alguns relatos na literatura apontam para as dificuldades dos pesquisadores em realizar análises de argumentos longos, ${ }^{13,20}$ especialmente quando adotam o Modelo de Toulmin. ${ }^{16}$ Por esse motivo, Kelly e Takao ${ }^{14}$ destacaram esse aspecto como uma das vantagens do Modelo que desenvolveram.

A Figura 1 apresenta a distribuição das proposições presentes nos cinco relatórios analisados de acordo com os níveis epistêmicos identificados nos textos. Cabe destacar que foram classificadas tanto no nível epistêmico I quanto no nível II as proposições dos alunos que fazem referência explícita à inserção de tabelas, nas quais dados relacionados aos compostos em estudo, interligando algumas de suas características, foram organizados. Os dados revelam que, em geral, as proposições se concentraram nos cinco primeiros níveis epistêmicos [n=27 (nível I), $\mathrm{n}=36$ (nível II), $\mathrm{n}=12$ (nível III), $\mathrm{n}=30$ (nível IV), $\mathrm{n}=16$ (nível V)]. O nível VI foi usado com menos frequência na escrita dos alunos $(n=8)$, provavelmente pelo fato de que proposições desse tipo não estejam ligadas diretamente à área de Química de Coordenação e, no contexto dos relatórios analisados, tenham servido principalmente para definir conceitos ou apresentar fórmulas, operações que não são feitas com frequência na seção Resultados e Discussão. Portanto, as proposições de níveis I, II e III (apresentação, descrição e comparação dos dados) e de níveis IV e V (afirmações teóricas específicas da área, podendo ser originárias dos dados apresentados pelos alunos (IV) ou não $(\mathrm{V}))$ foram as mais constantes nos relatórios.

Kelly e Takao ${ }^{14}$ estabeleceram dois critérios para avaliar a qualidade dos argumentos dos alunos. O primeiro critério diz respeito à distribuição das proposições através dos seis níveis epistêmicos. De acordo esses autores, argumentos que distribuem as proposições entre os níveis epistêmicos de maneira balanceada seriam considerados como relativamente fortes. Em outras palavras: um bom argumento nem enfocará apenas a descrição de dados sem informações teóricas para interpretá-los, nem fará afirmações teóricas sem dados suficientes para sustentá-las. O segundo critério diz respeito à relação entre proposições que se referem à apresentação de dados (nível I) e as que fazem afirmações teóricas específicas da área em estudo (níveis IV e V). Foram considerados mais fortes os argumentos que apresentam muitas fontes de dados (nível I) em relação às afirmações teóricas (níveis IV e V) do que aqueles que fizeram muitas afirmações teóricas com pequena referência de dados.

Ambos os critérios foram utilizados para avaliar a qualidade dos textos produzidos pelos alunos. Em relação ao segundo critério, os resultados demonstraram que os alunos apresentaram quantidade semelhante de dados - para o nível $\mathrm{I}, \mathrm{n}=5$ nos relatórios 1,4 e 5 , e $\mathrm{n}=6$ nos relatórios 2 e 3 -, porém apresentaram números diferentes de afirmações teóricas. Dessa forma, consideramos mais fortes os argumentos que apresentaram um número maior de afirmações teóricas. Nos casos em que os alunos fizeram poucas afirmações teóricas, observamos a não correlação de dados coletados nos experimentos com a base teórica da área na elaboração de suas conclusões.

Como mostra a Figura 1 as proposições são distribuídas de maneira relativamente balanceada nos relatórios 2, 3, 4 e 5. Além disso, são apresentadas 8, 12, 14 e 7 afirmações teóricas (níveis IV e V) em cada relatório, respectivamente. Isto indica que os estudantes elaboraram seus argumentos escritos de forma relativamente sistemática, apresentando dados, fazendo comparações entre os compostos de cobalto e usando evidências para apoiar suas afirmações teóricas.

A distribuição das proposições apresentadas na Figura 1 também revela que nenhuma afirmação relacionada ao nível epistêmico VI foi identificada no relatório 1 e que existem apenas cinco afirmações teóricas nesse relatório. Isto indica que os alunos que elaboraram o relatório apresentaram justificativas para as conclusões sobre os dados que obtiveram no laboratório de forma menos extensa que os demais alunos. Em outras palavras, eles não criaram um argumento forte, no qual os dados são extensivamente usados e correlacionados com a base teórica da área para justificar conclusões. O Modelo em questão permitiu, portanto, que essa distinção fosse observada.
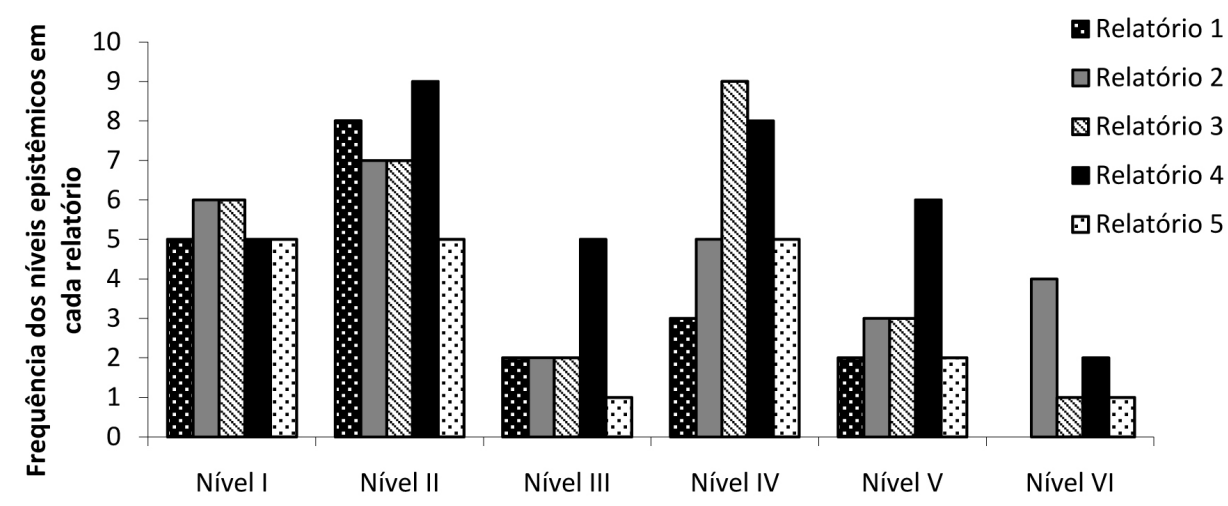

Níveis Epistêmicos

Figura 1. Distribuição, nos níveis epistêmicos, das proposições presentes nos relatórios dos alunos matriculados na disciplina experimental da área de Química Inorgânica 
Tabela 3. Distribuição dos níveis epistêmicos nas proposições apresentadas no Relatório 3, indicado na Figura 1

\begin{tabular}{|c|c|c|c|}
\hline Número & Proposição & $\begin{array}{l}\text { Justificativa para classificação da } \\
\text { proposição no nível epistêmico }\end{array}$ & $\begin{array}{c}\text { Nível } \\
\text { epistêmico }\end{array}$ \\
\hline
\end{tabular}

RESULTADOS E DISCUSSÃO

Espectrometria de Infravermelho

1 Para a caracterização do nitro e nitritopenta-amino Co(III) utilizou-se inicialmente a técnica de Espectrometria de Infravermelho, a partir das pastilhas feitas com amostra de $\mathrm{KBr}$.

Foram feitas as atribuições das bandas de infravermelho de acordo com a literatura, como é mostrado nas tabelas seguintes: 4 tabelas.

Quando comparados os espectros de nitro e nitrito Co(III), observa-se que a maioria das bandas obtidas é semelhante, porém no espectro obtido para o nitritopenta-amino Co(III) observa-se uma banda de média intensidade de $446,710 \mathrm{~cm}^{-1}$ correspondente à deformação axial da ligação Co-ONO, ou seja, o ligante coordenado pelo átomo de $\mathrm{O}$.

5 É possível observar também a presença de duas bandas distintas de N-O, mostrando que nesse complexo o ligante O-N-O está presente.

6 Já no espectro do nitropenta-amino Co(III) essas bandas não estão presentes, podendo ser observadas apenas bandas que evidenciam a presença apenas do ligante nitro, coordenado pelo $\mathrm{N}$.

Condutividade Eletrolítica

Realizou-se o teste de condutividade para cada composto e os dados foram adicionados na Tabela 6.

8

No teste para o trioxalato, verificou-se a solubilidade do composto sintetizado em éter, metanol, nitrobenzeno, álcool, acetona e acetonitrila, obtendo-se pouca solubilidade em nitrobenzeno.

No teste de condutividade, usou-se nitrobenzeno, que não forneceu um valor apreciável, porque apesar deste solvente solubilizar um pouco o composto, ele não é capaz de dissociar, logo não se tem a proporção de íons suficientes, ou íons em solução.

Ponto de Fusão

Espectrometria de Ultravioleta Visível

11 Na análise do espectro dos compostos na região do ultravioleta visível verificou-se a presença de duas bandas d-d para cada um, as quais são permitidas pela regra de seleção de Laporte e que ocorrem entre o estado fundamental e os estados excitados que apresentam mesma multiplicidade, de acordo com o diagrama de Tanabe-Sugano.

Os comprimentos de onda são mostrados nas tabelas abaixo, assim como as atribuições das transições feitas pelo diagrama: 4 tabelas.

Trioxalato de Hexa-amino Co(III): no teste de U.V. obtiveram-se valores abaixo do branco, indicando que o padrão influenciava na medida dos valores de absorbância, pelo fato de o branco ter uma coloração semellhante à do solvente, nitrobenzeno, utilizado.

Valores de Dq: estes valores indicam o desdobramento dos orbitais do íon metálico devido ao efeito do ligante sobre ele (série espectroquímica (Dq crescente)).

Tabela com valores de Dq dos complexos

Pela série espectroquímica apresentada acima os complexos Nitropenta-amino Co(III) e Nitritopenta-amino Co(III) deveriam apresentar o Dq superior ao do Trisetildiamino Co(III), no entanto, o que se observa é o contrário.
Referência às condições nas quais o composto foi caracterizado.

Referência explícita à inserção de figuras.

Referência explícita à inserção de tabelas nas quais dados relacionados aos compostos em estudo, indicando algumas de suas características, foram organizados.

Comparação entre características dos compostos apresentados em uma das tabelas.

Afirmação teórica com base nos dados apresentados pelos alunos.

Comparação entre características dos complexos e afirmação teórica com base nos dados apresentados pelos alunos.

Referência explícita à inserção de tabela, na qual dados relacionados aos compostos em estudo, indicando algumas das suas características, foram organizados.

Referência às condições nas quais a solubilidade dos compostos foi testada.

Afirmação teórica com base nos dados apresentados pelos alunos.

Referência explícita à inserção de tabela, na qual dados relacionados aos compostos em estudo, indicando algumas de suas características, foram organizados.

Afirmação teórica com base nos dados apresentados pelos alunos, seguida de outra afirmação teórica específica para a área de Química de Coordenação, mas não fundamentada diretamente em dados apresentados pelos alunos.

Referência explícita à inserção de tabelas, nas quais dados relacionados aos compostos em estudo, indicando algumas de suas características, foram organizados.

Referência a uma característica do complexo e afirmação teórica com base nos dados apresentados pelos alunos.

Afirmação teórica específica para compostos de coordenação, seguida de tabela, na qual dados relacionados aos compostos em estudo, indicando algumas de suas características, foram organizados.

Afirmação teórica com base nos dados apresentados pelos alunos.
N.A.

I

I

II

III

IV

III

IV

I

II

N.A.

IV

I II

IV 
Tabela 3. Continuação

\begin{tabular}{|c|c|c|c|}
\hline Número & Proposição & $\begin{array}{l}\text { Justificativa para classificação da } \\
\text { proposição no nível epistêmico }\end{array}$ & $\begin{array}{l}\text { Nível } \\
\text { epistêmico }\end{array}$ \\
\hline \multicolumn{4}{|c|}{ RESULTADOS E DISCUSSÃO } \\
\hline \multicolumn{4}{|c|}{ Espectrometria de Ultravioleta Visível } \\
\hline 16 & $\begin{array}{l}\text { O Penta-aminocloro Co(III) deveria possuir Dq maior do que o Dq do complexo cujo } \\
\text { ligante é o carboxilato, provavelmente o íon } \mathrm{Cl}^{-} \text {seja o responsável pela sua diminuição. }\end{array}$ & $\begin{array}{l}\text { Afirmação teórica com base nos dados } \\
\text { apresentados pelos alunos. }\end{array}$ & IV \\
\hline 17 & $\begin{array}{l}\text { O Nitropenta-amino Co(III) deve possuir Dq superior ao do Nitropenta-amino Co(III) } \\
\text { porque é um ambidentado, ora liga-se com um O, ora liga-se com outro. }\end{array}$ & $\begin{array}{l}\text { Afirmação teórica com base nos dados } \\
\text { apresentados pelos alunos. }\end{array}$ & IV \\
\hline \multicolumn{4}{|c|}{ Susceptibilidade Magnética } \\
\hline 18 & $\begin{array}{l}\text { Esta análise foi realizada apenas para o isômero II, pois não houve quantidade suficiente } \\
\text { do isômero I para a realização da mesma. }\end{array}$ & $\begin{array}{l}\text { Referência a não realização de uma } \\
\text { determinada análise. }\end{array}$ & N.A \\
\hline 19 & Porém, como são isômeros, ambos têm a mesma suscetibilidade magnética. & $\begin{array}{l}\text { Afirmação específica para compostos de } \\
\text { coordenação. }\end{array}$ & $\mathrm{V}$ \\
\hline 20 & $\begin{array}{l}\mathrm{O} \text { valor obtido no aparelho foi } 0,008.10-5 \text { a } 25^{\circ} \mathrm{C} \text {, com esse dado calculou-se o } \\
\text { número de elétrons desemparelhados, através das seguintes fórmulas. }\end{array}$ & $\begin{array}{c}\text { Referência a uma determinada característica } \\
\text { do complexo, seguida de afirmação geral, } \\
\text { não específica para compostos de cobalto } \\
\text { (uso de fórmulas contidas em livros } \\
\text { didáticos). }\end{array}$ & $\begin{array}{l}\text { II } \\
\text { VI }\end{array}$ \\
\hline 21 & $\begin{array}{l}\text { O número de elétrons obtidos foi igual a zero e, portanto, os complexos não possuem } \\
\text { elétrons desemparelhados, sendo diamagnéticos. }\end{array}$ & $\begin{array}{l}\text { Afirmação teórica com base nos dados } \\
\text { apresentados pelos alunos. }\end{array}$ & IV \\
\hline
\end{tabular}

As discussões tecidas até então indicam que o Modelo de Kelly e Takao ${ }^{14}$ é útil para analisar a qualidade da escrita científica dos alunos, evidenciando, dentre outros aspectos, a quantidade e a natureza das informações que os alunos apresentam em seus textos (dados e teorias) e a maneira como articulam essas informações, de forma a construir argumentos fortes. Cabe destacar, no entanto, que, assim como outros modelos de análise de argumentos, ${ }^{16,21}$ esse não permitiu avaliar a coerência, ou a verdade, nas proposições apresentadas pelos alunos. Assim, é impossível fazer afirmações, apenas através do seu uso, sobre o domínio dos alunos a respeito do conteúdo científico necessário para a construção dos relatórios.

\section{CONSIDERAÇÕES FINAIS}

Objetivamos nesta pesquisa avaliar a qualidade da escrita científica de alunos de graduação em Química através do Modelo de Kelly e Takao. ${ }^{14}$ Esse Modelo foi empregado para analisar, de acordo com os níveis epistêmicos, os argumentos construídos pelos alunos na elaboração de relatórios de laboratório de atividades experimentais da área de Química Inorgânica. Os resultados da análise permitiram a elaboração das seguintes considerações e implicações para o ensino de ciências:

- Os alunos apresentaram argumentos científicos fundamentados em dados e afirmações teóricas. Isto indica sua relativa compreensão do poder retórico da utilização de dados e evidências para dar sustentação às explicações científicas. Assim, foi possível analisar através do Modelo como os alunos correlacionaram, em maior ou menor extensão, dados e informações teóricas para construir o texto científico.

- Os resultados também demonstraram que o Modelo é efetivo para a avaliação de argumentos escritos produzidos em outras disciplinas e em outras atividades retóricas distintas daquelas originalmente analisadas por Kelly e Takao ${ }^{14}$ na área de Oceanografia. Cabe destacar que este é o primeiro trabalho, fora desta área, que se pauta no referido Modelo para avaliar argumentos escritos por alunos de graduação.

- A análise revelou a capacidade dos alunos em elaborar argumentos científicos, especialmente em relação à maneira como eles empregaram os dados experimentais como evidências para sustentar suas explicações sobre a natureza e estrutura dos compostos de cobalto. No entanto, apenas através dessa análise não é possível dizer se tais argumentações estão corretas ou não. Esta é uma das principais limitações do Modelo de Kelly e Takao ${ }^{14}$ e representa um espaço aberto para futuras pesquisas que se proponham a aprimorar ou elaborar modelos analíticos capazes de contemplar a pertinência dos conteúdos científicos apresentados nos argumentos científicos. Nesse sentido, estão em andamento em nosso grupo de pesquisa trabalhos que visam a produção e o aprimoramento de modelos que abarquem as questões conceituais, estruturais e os movimentos retóricos dos textos científicos.

\section{MATERIAL SUPLEMENTAR}

O material didático contendo instruções sobre a estrutura de relatórios de laboratório encontra-se disponível gratuitamente em http://quimicanova.sbq.org.br, na forma de arquivo PDF.

\section{AGRADECIMENTOS}

À CAPES e à FAPESP (Processo 07/06657-0) pelo apoio financeiro.

\section{REFERÊNCIAS}

1. Huang, H.; Int. J. Sci. Math. Educ. 2006, 4, 391; Jorge, A. S.; Puig, N. S.; Enseñanza de las Ciencias 2000, 18, 405; Villani, C. E. P.; Nascimento, S. S.; Investigações em Ensino de Ciências 2003, 8, 187.

2. Lemke, J. L.; Aprender a Hablar Ciencia, Paidós: Buenos Aires, 1997.

3. Florence, M. K.; Yore, L. D.; J. Res. Sci. Teach. 2004, 41, 637.

4. Gunel, M.; Hand, B.; Prain, V.; Int. J. Sci. Math. Educ. 2007, 5, 615.

5. Massi, L.; Abreu, L. N.; Queiroz, S. L.; Revista Electrónica de Enseñanza de las Ciencias 2008, 7, 704.

6. Zucco, C.; Pessine, F. B. P.; de Andrade, J. B.; Quim. Nova 1999, 22, 454.

7. Santos, G. R.; Sá, L. P.; Queiroz, S. L.; Quim. Nova 2006, 29, 1121.

8. Queiroz, S. L.; Quim. Nova 2001, 24, 143.

9. Oliveira, J. R. S.; Queiroz, S. L.; Quim. Nova 2008, 31, 1263. 
10. Oliveira, J. R. S.; Queiroz, S. L.; Revista Electrónica de Enseñanza de las Ciencias 2007, 6, 673.

11. Oliveira, J. R. S.; Queiroz, S. L.; Atas do V Encontro Nacional de Pesquisa em Educação em Ciências, Bauru, Brasil, 2005.

12. Luz Júnior, G. E.; Sousa, S. A.; Moita, G. C.; Moita Neto, J. M.; Quim. Nova 2004, 27, 164.

13. Sampson, V.; Clark, D. B.; Sci. Educ. 2008, 92, 447.

14. Kelly, G. J.; Takao, A.; Sci. Educ. 2002, 86, 314.

15. Oliveira, J. R. S.; Queiroz, S. L.; Comunicação e Linguagem Científica: guia para estudantes de química, Editora Átomo: Campinas, 2007.
16. Toulmin, S. E.; Os Usos do Argumento, Martins Fontes: São Paulo, 2001.

17. Sá, L. P.; Queiroz, S. L.; Quim. Nova 2007, 30, 2035.

18. Simon, S.; Int. J. Res. Math. Educ. 2008, 31, 277; von Aufschnaiter, C.; Erduran, S.; Osborne, J.; Simon, S.; J. Res. Sci. Teach. 2008, 45, 101.

19. Latour, B.; Ciência em Ação: como seguir cientistas e engenheiros sociedade afora, Editora UNESP: São Paulo, 2000.

20. Sandoval, W.; Millwood, K.; Cognition and Instruction 2005, 23, 23.

21. Lawson, A.; Int. J. Sci. Educ. 2003, 25, 1387. 


\section{ESCRITA CIENTÍFICA DE ALUNOS DE GRADUAÇÃO EM QUÍMICA: ANÁLISE DE RELATÓRIOS DE LABORATÓRIO}

Jane Raquel Silva de Oliveira e Alzir Azevedo Batista

Departamento de Química, Universidade Federal de São Carlos, Rod. Washington Luiz, km 235, 13565-905 São Carlos - SP, Brasil Salete Linhares Queiroz*

Instituto de Química de São Carlos, Universidade de São Paulo, CP 780, 13560-970 São Carlos - SP, Brasil

\section{MATERIAL DIDÁTICO: \\ Estrutura de Relatórios de Laboratório}

Parte 1 As prineipais secões do relatório de laboratório

\section{Relatórios de Lahoratório de Ensino}

São trabalhos frequentes em disciplinas experimentais. Relatam as atividades desenvolvidas no laboratório de ensino, os resultados obtidos, sua discussão e as conclusões do experimento. Sua forma de apresentação é variável de acordo com a disciplina, mas geralmente constam das seguintes seções:

- CAPA (Nome da Instituição e Disciplina, Título do Experimento, Nome do aluno)

- RESUMO

- INTRODUÇÃo

- MATERIAIS E MÉTODOS (OU PARTE EXPERIMENTAL)

- REsultados e discussão

- conclusões

- REFERÊNCIAS BIBLIOGRÁFICAS

\section{Principais Garacteristicas das Sệ̃es do Relatório de Laboratório}

\begin{tabular}{|c|c|}
\hline SEÇÃO & PRINCIPAIS CARACTERÍSTICAS \\
\hline Título & $\begin{array}{l}\text { - É elaborado de forma a refletir o conteúdo da atividade prática (resultado } \\
\text { principal, tipo de substância analisada ou método utilizado). } \\
\text { - Geralmente é claro e objetivo, sem o uso de expressões vagas que pouco } \\
\text { contribuem para a descricão da atividade. }\end{array}$ \\
\hline Resumo & $\begin{array}{l}\text { - A atividade realizada é apresentada de forma sintética. } \\
\text { - Geralmente são descritos: a questão abordada na atividade; os métodos utilizados; } \\
\text { os principais resultados. } \\
\text { - Abreviações pouco conhecidas e citações bibliográficas não costumam estar } \\
\text { presentes. }\end{array}$ \\
\hline Introdução & $\begin{array}{l}\text { - São apresentadas a contextualização do experimento (revisão de literatura sobre } \\
\text { aspectos teóricos relacionados ao assunto abordado na atividade) e sua } \\
\text { justificativa. }\end{array}$ \\
\hline $\begin{array}{l}\text { Materiais e } \\
\text { Métodos } \\
\text { (Parte } \\
\text { Experimental) }\end{array}$ & $\begin{array}{l}\text { - São apresentadas as amostras (tipos, quantidades), reagentes (procedência, } \\
\text { concentração das soluções), equipamentos (modelo e procedência) e outros } \\
\text { materiais utilizados na atividade prática. } \\
\text { - Os procedimentos experimentais adotados (metodologia) e tratamentos } \\
\text { estatísticos realizados são descritos. }\end{array}$ \\
\hline Resultados & $\begin{array}{l}\text { - São apresentados os dados obtidos no experimento, sem comentários ou } \\
\text { interpretações. } \\
\text { - Os dados são organizados em gráficos e tabelas. As legendas explicativas de } \\
\text { tabelas, gráficos e figuras são apresentadas no trabalho e citadas no corpo do } \\
\text { texto. } \\
\text { - O tratamento estatístico empregado é descrito. }\end{array}$ \\
\hline Discussão & $\begin{array}{l}\text { - Os dados obtidos são analisados/ interpretados. } \\
\text { - Os resultados são discutidos de acordo com o que foi proposto (objetivos da } \\
\text { atividade prática realizada) e também de acordo com outros dados da literatura. } \\
\text { - São apresentadas discussões sobre a relevância dos resultados e as principais } \\
\text { conclusões obtidas. }\end{array}$ \\
\hline Conclusão & $\begin{array}{l}\text { - São descritas de forma objetiva apenas as principais conclusões, sem repetição } \\
\text { dos dados obtidos }\end{array}$ \\
\hline $\begin{array}{c}\text { Referências } \\
\text { Bibliográficas }\end{array}$ & $\begin{array}{l}\text { - São apresentadas segundo as normas estabelecidas pela instituição. } \\
\text { - São apresentadas em numeração decimal seqüenciada (em sistema de citação } \\
\text { numérica) ou por ordem alfabética (em sistema de citação autor-data). }\end{array}$ \\
\hline
\end{tabular}

*e-mail: salete@iqsc.usp.br 
A importância das citações e referências bibliográficas nos textos científicos pode ser atribuída, dentre outros, aos seguintes aspectos:

- por questões éticas deve-se sempre citar o autor responsável por uma dada informação que não seja sua;

- para fornecer ao leitor o "caminho" (referência) para a busca de um trabalho original completo cuja parte foi citada no seu texto;

- para que o autor resguarde-se da responsabilidade de fornecer informações eventualmente incorretas oriundas de outros trabalhos.

\section{Formas de Apresentạ̧ão das Gitạ̄ȭes}

As citações podem ser diretas (quando, no texto, são citados trechos iguais ao do trabalho original) ou indiretas (quando o autor apresenta, com suas próprias palavras, dados ou informações de outros trabalhos).

- Citação Direta

[...] ao assumir que "é na interação entre conhecimento teórico e o conhecimento da prática que se constrói o conhecimento profissional do professor" (Alarcão ${ }^{101}$ ), tal proposição também incentiva a formação de professores do ensino médio [...]. (Química Nova, v.25, Supl.1, p.22, 2002)

\section{- Citação Indireta}

Ou seja, de acordo com Sargentini et al. ${ }^{35}$, o complexo metal-MO tende a se estabilizar em função do tempo, ocorrendo rearranjos inter e/ou intramoleculares, com transferência de espécie metálica para sítios de complexação mais internos das moléculas húmicas. (Química Nova, v.30, n.2, p.279, 2007)

As citações podem seguir os seguintes sistemas de apresentação:

- Sistema de Citação Numérico: quando os trabalhos citados são numerados sequencialmente de acordo com a ordem em que aparecem no texto e as referências bibliográficas aparecem numeradas sequencialmente ao final do texto.

Para os produtores de açúcar a presença de dextranas é o principal indicador do grau de deterioração da cana pela ação da bactéria Leuconostoc mesenteroides ${ }^{1,2} \cdot[\ldots]$

Nas indústrias de bebidas é bem conhecido que as dextranas podem conduzir à formação de precipitados e alterações na estabilidade do produto acabado ${ }^{3-5} \cdot[\ldots]$

\section{REFERÊNCIAS}

1. Eggleston, G.; Food Chem. 2002, 78, 95.

2. Eggleston, G.; Legendre, B.; Tew, T.; Food Chem. 2004, 87, 119.

3. Tajchakavit. S.; Boye, J. I.; Bélanger, D.; Couture, R.; Food Res. Int. 2001, 34, 431.

4. Kruif. C. G.; Tuinier, R.; Food Hydrocolloids 2001, 15, 555.

5. Chistiane, F. B.; Peter, A. I.; J. Agric. Food Chem. 1992, 40, 227. (Química Nova, v.30, n.5, p.1115-1118, 2007)

- Sistema de Citação Autor-Data: quando na citação apresenta-se o sobrenome do autor, seguido do ano de publicação. O sobrenome do autor pode, ou não, fazer parte da sentença. As referências bibliográficas são apresentadas em ordem alfabética ao final do texto. 


\begin{abstract}
Das inúmeras espécies vegetais utilizadas, com sucesso, no controle de pragas agrícolas, algumas são pertencentes à família Annonaceae (HERNÁNDEZ, 2001). [...]

Lemos et al. (1992) e Fournier et al. (1994) também investigaram o potencial antimicrobiano do óleo essencial da raiz e do fruto, respectivamente. (Química Nova, v.30, n.4, p.838, 2007, adaptado)
\end{abstract}

\title{
REFERÊNCIAS
}

FOURNIER, G.; HADJIAKHOONDI, A.; LEBOEUF, M.; CAVE, A.; CHARLES, B.; FOURNIAT, J.; Phytotherapy Res. 1994, 8, 166. HERNÁNDEZ, C. R.; Plantas contra Plagas - potencial práctico de ajo, anona, nim, chile y tabaco, RAPAM: Estado de México, 2001. LEMOS, T. L. G.; MONTE, F. J. Q.; MATOS, F. J. A.; ALENCAR, J. W.; CRAVEIRO, A. A.; BARBOSA, R. C. S. B.; LIMA, E. O.; Fitoterapia 1992, 63, 266.

\section{Apresentação das Referêneias Bibliográficas}

Cada instituição costuma ter suas normas próprias para apresentação das referências bibliográficas. Em geral, adotam-se as normas estabelecidas pela Associação Brasileira de Normas Técnicas (ABNT). O documento mais recente da ABNT sobre citações e referências bibliográficas é a NBR 6023/2002, o qual deverá ser seguido para a elaboração dos relatórios de laboratório. A seguir são descritas resumidamente as formas de apresentação de referências de alguns tipos de trabalhos comumente citados em relatórios de laboratório.

\section{- Artigos em periódicos}

AUTOR(ES) DO ARTIGO. Título do artigo. Nome da revista (itálico ou negrito), local, volume, número, páginas inicial-final, ano.

VIEIRA JUNIOR, G. M.; SILVA, H. R.; BITTENCOURT, T. C.; CHAVES, M. H.; SIMONE, C. A. Terpenos e ácidos graxos de Dipteryx lacunifera Ducke. Química Nova, v.30, n.7, p.1658-1662, 2007.

\section{- Livros (em um todo)}

SOBRENOME, Nome. Título (negrito ou itálico): subtítulo (se houver). Tradutor (se houver). Edição. Local: Editora, ano, número de páginas.

ATKINS, P.; JONES, L. Princípios de Química: questionando a vida moderna e o meio ambiente. 3.ed. Porto Alegre: Bookman, 2006. 968p.

\section{- Capítulos de livros}

AUTOR DO CAPÍTULO, Nome. Título do capítulo. In: AUTOR DO LIVRO, Nome. Título do livro. Edição. Local: Editora, ano, pág. Inicial-final.

SILVA, L. H. A.; ZANON, L. B. A Experimentação no Ensino de Ciências. In: SCHNETZLER, R. P.; ARAGÃO, R. M. R. Ensino de Ciências: fundamentos e abordagens. Campinas: R. Vieira Gráfica e Editora, 2000. p.120-153.

\section{- Páginas da internet}

AUTOR. Título. Disponível em: < endereço eletrônico>. Acesso em: dia mês (abreviado) ano.

PESQUISA FAPESP. Sem eles não há avanço. Disponível em: $<\mathrm{http} / / /$ www.revistapesquisa.fapesp.br/?art=3445\&bd=1\&pg=1>. Acesso em: 28 fev. 2008. 


\section{Principais Tipos de Gitą̧ões}

Quanto à sua função no texto científico, as citações podem ser de vários tipos. A seguir apresentamos, dentre os tipos de citações usuais nos artigos científicos, aqueles que constam em relatórios de laboratório, destacando sua importância e indicando em que seções costumam estar presentes:

\begin{tabular}{|c|c|c|}
\hline TIPOS DE CITAÇÕES & IMPORTÂNCIA & LOCALIZAÇÃO NO TEXTO \\
\hline $\begin{array}{l}\text { Citações que constituem o } \\
\text { paradigma adotado } \\
\text { (informaçōes já } \\
\text { consolidadas) }\end{array}$ & $\begin{array}{l}\text { Demonstram o conhecimento do } \\
\text { autor sobre o tema em questão e } \\
\text { servem para contextualizar o } \\
\text { trabalho }\end{array}$ & $\begin{array}{l}\text { São encontradas principalmente } \\
\text { na Introdução }\end{array}$ \\
\hline \multicolumn{3}{|c|}{$\begin{array}{l}\text { As principais formas iônicas de mercúrio, } \mathrm{Hg}^{2+} \text { e } \mathrm{CH}_{3} \mathrm{Hg}^{+} \text {, são fortemente complexadas por ácidos } \\
\text { húmicos, fúlvicos e outras moléculas orgânicas presentes nos ecossistemas naturais }{ }^{8,9} \text {. No solo esses } \\
\text { complexos organo-mercuriais são adsorvidos nas superfícies das argilas e na matriz sólida, que } \\
\text { consiste principalmente de óxidos de ferro, alumínio e manganês e substâncias húmicas }{ }^{10} \text {. (Química } \\
\text { Nova, v. } 30, \text { n.2, p. } 274,2007 \text { ) }\end{array}$} \\
\hline $\begin{array}{l}\text { ções que apresentam o } \\
\text { método utilizado }\end{array}$ & $\begin{array}{l}\text { Demonstram que o trabalho é } \\
\text { pautado em metodologia } \\
\text { comprovada na literatura e } \\
\text { adequada àquele estudo }\end{array}$ & $\begin{array}{l}\text { Geralmente são encontradas em } \\
\text { Materiais e Métodos }\end{array}$ \\
\hline \multicolumn{3}{|c|}{$\begin{array}{l}\text { [...] o método descrito por Roberts }{ }^{8,9} \text { é muito popular em laboratórios de controle de qualidade de } \\
\text { indústrias que adicionam açúcar em seus produtos. Seguindo esta metodologia }{ }^{8-10} \text {, o preparo da curva } \\
\text { de calibração foi efetuado [...]. (Química Nova, v.30, n.5, p.1115, 2007) }\end{array}$} \\
\hline $\begin{array}{l}\text { Citações de trabalhos com } \\
\text { resultados semelhantes }\end{array}$ & $\begin{array}{l}\text { Reforçam o trabalho do autor; } \\
\text { provam que outros autores } \\
\text { chegaram a conclusões similares }\end{array}$ & $\begin{array}{l}\text { São observadas principalmente em } \\
\text { Resultados e Discussão } \\
\text { (comparação de dados) }\end{array}$ \\
\hline \multicolumn{3}{|c|}{$\begin{array}{l}\text { Esses resultados estão de acordo com os obtidos por Oliveira }{ }^{15} \text { e Luo e } \text { Netravali }^{16} \text { ao estudarem a } \\
\text { degradação radiolítica de PHB. (Química Nova, v.30, n.7, p.1586, 2007) }\end{array}$} \\
\hline $\begin{array}{l}\text { Citações de trabalhos com } \\
\text { resultados discordantes }\end{array}$ & $\begin{array}{l}\text { Mostram (no mínimo) que o tema } \\
\text { é conflitante, ou merece novos } \\
\text { testes, ou os resultados são } \\
\text { inovadores }\end{array}$ & $\begin{array}{l}\text { Também são observadas em } \\
\text { Resultados e Discussão (para } \\
\text { comparação de dados). São } \\
\text { apresentadas na Introdução como } \\
\text { justificativa }\end{array}$ \\
\hline \multicolumn{3}{|c|}{$\begin{array}{l}\text { Entretanto, o óleo das folhas e frutos analisado neste trabalho apresentou um perfil químico diferente, } \\
\text { quando comparado com aqueles relatados na literatura }{ }^{16-19} \text {. } \\
\text { (Química Nova, v.30, n.4, p.839, 2007) }\end{array}$} \\
\hline
\end{tabular}




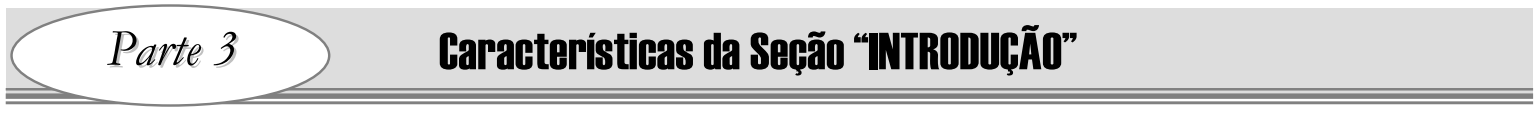

A seção Introdução contém informações que servem para apresentar a área da ciência na qual o trabalho se "encaixa" e contextualizar o tema principal (o que a literatura diz a respeito). Ademais, tais informações são utilizadas para justificar a importância do trabalho realizado. Nesta seção são descritos também os objetivos do trabalho.

Em relatórios de laboratório de ensino, a Introdução pode conter, por exemplo, os seguintes elementos:

- REVISÃO DE literatura sobre a subStÂNCIA/ MATERIAL ANALISADO OU OBTIDO: características químicas relatadas na literatura, importância, aplicações.

- ASPECTOS SOBRE A TÉCNICA/ METODOLOGIA UTILIZADA: histórico, importância/ vantagens, dificuldades e limitações do método, exemplos de aplicações e outras informações relevantes para a compreensão do experimento.

- JUSTIFICATIVA: importância do experimento realizado (usam-se como base as informações fornecidas nos parágrafos anteriores).

- OBJETIVOS DO EXPERIMENTO.

Como exemplo, apresentamos a seguir trechos extraídos da seção Introdução de um artigo científico da revista Química Nova:

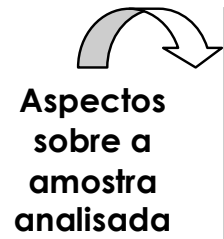

O óleo diesel é o principal produto do fracionamento do petróleo no Brasil. Esse combustível é constituído por hidrocarbonetos parafínicos, olefínicos e aromáticos com cadeia carbônica de 6 a 30 átomos. Alguns compostos apresentam também enxofre, oxigênio e nitrogênio. Já o biodiesel é constituído por ésteres alquílicos obtidos, principalmente, a partir da transesterificação de óleos vegetais ou gordura animal [...]. Entretanto, este processo é raramente utilizado uma vez que as fontes de triglicerídeos são mais disponíveis do que de ácidos graxos ${ }^{1}$. O biodiesel possui algumas vantagens sobre o diesel, tais como alto número de cetano; alto ponto de fulgor; menor emissão de material particulado, monóxido de carbono e dióxido de carbono; biodegradabilidade; além de ser isento de enxofre e de compostos aromáticos ${ }^{2,3}$.

\section{2 Justificativa}

A Agência Nacional de Petróleo, Gás Natural e Biocombustíveis (ANP), órgão regulador, aponta para a necessidade de se avaliar a qualidade desta mistura a partir da realização de análises laboratoriais e emissão de Boletim de Conformidade. O desenvolvimento de metodologias para análise de misturas biodiesel:diesel passa a ser um recurso estratégico no controle de qualidade do combustível a ser disponibilizado nos postos de abastecimento.

Dentre as ferramentas analíticas disponíveis para identificação e quantificação de compostos em misturas, pode-se destacar a Cromatografia Gasosa de Alta Resolução acoplada à Espectrometria de Massas (CGAR-EM), a Espectroscopia na Região do Infra-Vermelho (IV) e do Ultra-Violeta (UV) e a Ressonância Magnética Nuclear (RMN).

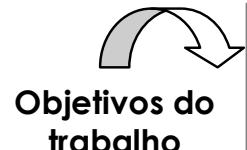
trabalho
O objetivo deste trabalho foi o desenvolvimento e a validação de uma metodologia de análise de misturas biodiesel:diesel empregando CGAR-EM no modo de análise por monitoramento seletivo de íons (MSI). 


\section{n \\ Aspectos \\ sobre a \\ substância \\ analisada}

Um grande interesse a respeito da ocorrência de silício em vegetais - em particular na casca de arroz - tem sido despertado nos últimos anos devido à possibilidade de produção de materiais de alto interesse tecnológico, como silício e sílica $\left(\mathrm{SiO}_{2}\right)$ de alta pureza, carbeto de silício $(\mathrm{SiC})$ e nitreto de silício $\left(\mathrm{Si}_{3} \mathrm{~N}_{4}\right)$, a partir da conversão térmica de precursores orgânicos naturais. [...] Portanto, a possibilidade de utilização desse abundante rejeito da agroindústria para a produção de materiais de interesse tecnológico é considerada promissora, tanto do ponto de vista econômico quanto ecológico, particularmente em países com grande produção de arroz, como o Brasil e a Índia ${ }^{2-5}$.

Mais recentemente, novos trabalhos fazendo uso de técnicas como espectroscopia por absorção no infra-vermelho (FTIR), espectroscopia de fotoelétrons excitados por raios X (XPS) e microscopia eletrônica (SEM e TEM) reforçaram a sugestão de uma conexão entre grupos silicatos e compostos orgânicos (especificamente monossacarídeos) na casca de $\operatorname{arroz}^{10,11}$. Com o uso de espectroscopia de alta resolução por ressonância magnética nuclear (RMN) de 13C e 29Si no estado sólido, foram apresentadas recentemente evidências diretas da conexão entre átomos de silício e grupos orgânicos na casca de arroz e também no endocarpo de babaçu ${ }^{11}$.

\section{R \\ Dentre as aplicações já descritas, deve-se acrescentar a possibilidade de aproveitamento da casca de arroz para a manufatura de carvão ativado. [...] O carvão ativado é um material poroso com elevada área superficial específica (ASE), garantindo grande capacidade de adsorção física de líquidos e gases ${ }^{12-14}$.}

\section{$\infty$ \\ Objetivo \\ Este trabalho teve por objetivo investigar o uso da casca de arroz para produção de carvão ativado, utilizando o método de ativação química com hidróxido de sódio $(\mathrm{NaOH})$ como agente ativador ${ }^{12,13,16}$.}

(Química Nova, v.30, n.7, p.1663, 2007)

Também podem ser acrescentadas à Introdução do relatório de laboratório de ensino, figuras apresentando estruturas químicas. Observe um exemplo:

Quimicamente, quitina e quitosana estão proximamente relacionadas desde que ambas são polissacarídeos lineares contendo as unidades 2-acetamido-2-desoxi-D-glicopiranose (GlcNAc) e 2amino-2-desoxi-D-glicopiranose $(G l c N)$ unidas por ligações glicosídeas do tipo $\beta(1 \rightarrow 4)$ conforme a Figura 1.

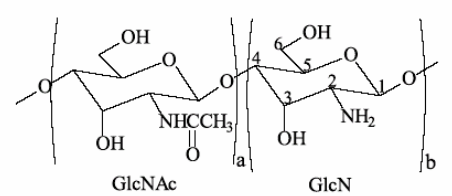

Figura 1. Estrutura química das unidades (a) 2-acetamido-2-desoxi-Dglicopiranose(GlcNAc) e (b) 2-amino-2-desoxi-Dglicopiranose $(\mathrm{GlcN})$ unidas por ligações glicosídeas $\beta(1 \rightarrow 4)$. A proporção de grupos a $e \mathrm{~b}$ distingue quitina de quitosana 


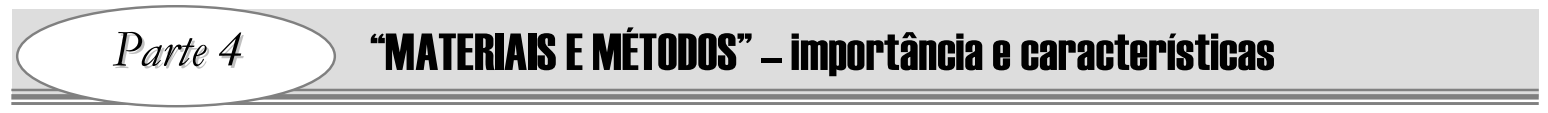

A seção Materiais e Métodos, também denominada Parte Experimental, é uma das principias seções de um relatório de laboratório de ensino, uma vez que exige, na maioria das vezes, um considerável grau de detalhamento dos materiais utilizados e dos procedimentos adotados. Sua finalidade é proporcionar ao leitor a capacidade de entender como o experimento foi desenvolvido e de reproduzi-lo, se desejar.

Alguns aspectos importantes devem ser lembrados quando da elaboração dessa seção:

- Devem ser descritos todos os materiais utilizados, incluindo marca dos reagentes, marca e número do modelo dos equipamentos utilizados. As amostras também devem ser apresentadas (quantidade, procedência, se recebeu tratamento prévio ou não).

- As soluções utilizadas e suas concentrações devem ser listadas. Em geral não há necessidade de descrever minuciosamente o preparo da maioria das soluções, a menos que seja uma solução que exija procedimentos especiais. Deve-se lembrar também de alertar sobre os cuidados especiais que devem ser tomados no manuseio de substâncias potencialmente perigosas.

- A referência do método utilizado deve ser citada. Os procedimentos realizados devem ser descritos no estilo "passo-a-passo" (ordem cronológica em que ocorreram), ressaltando-se as condições experimentais ( $\mathrm{pH}$, temperatura etc) e eventuais modificações no método.

- Podem ser apresentadas figuras para ilustrar algumas partes do experimento, ou esquema de algumas reações químicas realizadas durante o experimento, ou ainda um fluxograma para esquematizar todos os procedimentos realizados.

- $\quad$ Deve ser dada atenção à nomenclatura das substâncias e unidades empregadas.

- Caso seja utilizado, o método estatístico empregado deve ser citado.

A seguir apresentamos trechos da Parte Experimental de um artigo da revista Química Nova que fornecem um exemplo de como estruturar esta seção em um relatório de laboratório de ensino. Observe que o autor subdividiu esta seção em partes de modo a torná-la mais organizada.

\section{Descrição dos Materiais}

\section{Materiais}

\section{Polímero}

Os poliésteres utilizados foram poli( $\beta$-hidroxibutirato)-PHB e poli( $\beta$-hidroxibutirato-co-valerato) - PHB-HV, fornecidos pela PHB Industrial S/A. O amido utilizado foi do tipo regular amidex 3001, fornecido pela Corn Products do Brasil. Os poliésteres e o amido foram utilizados sem nenhum tratamento prévio.

\section{Reagentes}

Os reagentes utilizados na preparação dos meios, todos da marca Vetec, foram: glicose P.A., cloreto de sódio, agar-agar, peptona bacteriológica, extrato de carne, hidróxido de bário, ácido clorídrico, hidróxido de sódio. Na desinfecção das blendas foi utilizado etanol (Synth).

\section{Descrição dos Métodos}

\section{Métodos}

Preparação das blendas

Os filmes de PHB/amido e PHB-HV/amido na composição 80/ $20 \mathrm{~m} / \mathrm{m}$ e filmes de PHB e PHB-HV puros apresentaram espessuras de $0,07+0,01 \mathrm{~mm}$, e foram obtidos através da técnica de evaporação do solvente de soluções do polímero em clorofórmio, nas seguintes condições: massa total: $0,98 \mathrm{~g}$; temperatura de controle: 50 ${ }^{\circ} \mathrm{C}$; tempo total de mistura: $16 \mathrm{~h}$; em sistema sob agitação e após completa dissolução, foram transferidos para placa de Petri (diâmetro de $11 \mathrm{~cm}$ ) na temperatura ambiente, sem controle da umidade. 
Descrição dos Métodos (Apresentação de figura para ilustrar o experimento. Citação da referência do método. Descrição dos equipamentos)

Ensaio de biodegradação

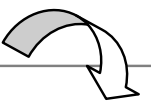

$\mathrm{O}$ monitoramento da produção de $\mathrm{CO}_{2}$ foi realizado em triplicata, segundo o teste de Sturm que consiste de um sistema composto por um compressor de ar, um reator e dois recipientes coletores de $\mathrm{CO}_{2}$, um colocado antes e outro após o reator, todos conectados por mangueiras (Figura 1), contendo 400 e $200 \mathrm{~mL}$, respectivamente, de solução de hidróxido de bário $1^{3}$.[...]

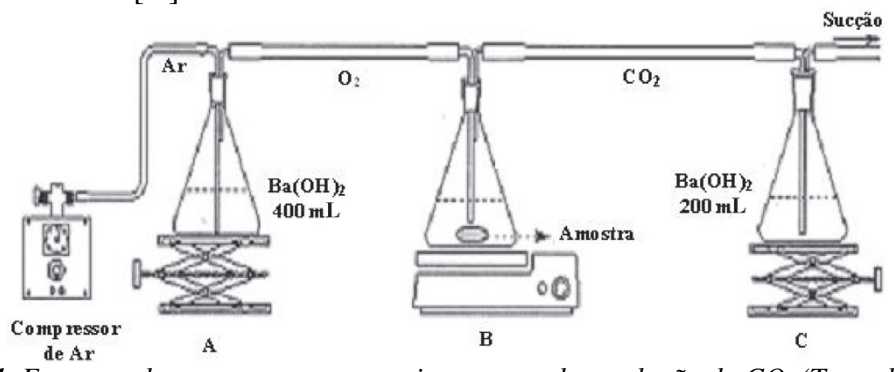

Figura 1. Esquema de montagem para monitoramento da produção do $\mathrm{CO}_{2}$ (Teste de Sturm)

Caracterização das blendas

Ressonância Magnética Nuclear (RMN)

Os ensaios de $\mathrm{RMN}^{1} \mathrm{H}$ para PHB e PHB-HV puro e suas blendas com amido, antes e após a biodegradação, foram realizados em um espectrômetro Variant Unit Plus-300 em uma freqüência de ressonância de 299,95 e 75,42 MHz, utilizando-se clorofórmio deuterado como solvente.

Espectroscopia no Infravermelho com Transformada de Fourier (FTIR)

Amostras de PHB/amido e PHB-HV/amido, antes e após a biodegradação, foram secadas e analisadas por infravermelho no equipamento de FT-IR Brucker modelo 1FS66, utilizando a técnica de pastilha de $\mathrm{KBr}$, para avaliação do Índice de Grupos Carboxílicos Terminais (IGCT) através da equação IGCT = (absorção a $3290 \mathrm{~cm}^{-}$ $\left.{ }^{1}\right)$ / (absorção a $\left.2970 \mathrm{~cm}^{-1}\right)$ [...].

Observe que, nestes outros exemplos a seguir, os autores acrescentaram à seção Materiais e Métodos o esquema da reação química desenvolvida ou fluxograma do experimento:

Uma dispersão a $1 \%$ de sulfato de condroitina foi preparada em água com $\mathrm{pH} 12 \mathrm{e}$ agitada por $2 \mathrm{~h}$ para permitir a máxima homogeneização. Em uma porção de $200 \mathrm{~mL}$ da dispersão foram adicionados $20 \mathrm{~mL}$ de uma solução $30 \%$ de trimetafosfato trisódico (TMFT). $\mathrm{O} \mathrm{pH}$ foi novamente ajustado para 12 e a agitação mantida por mais $2 \mathrm{~h} 20$. O esquema da reação está apresentado na Figura 2.<smiles>CC(O)CC(C)O</smiles>

Sulfato de Condroitina
(SC)

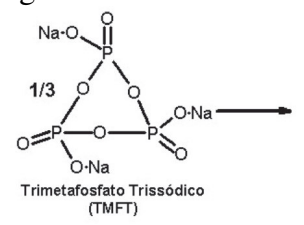

Figura 2. Reação entre sulfato de condroitina $e$ trimetafosfato trissódico.

(Química Nova, v.30, n.2, p.312-317, 2007)

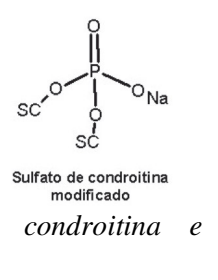

A Figura 1 mostra um esquema da seqüência das etapas de preparação das amostras PMF e PIA.

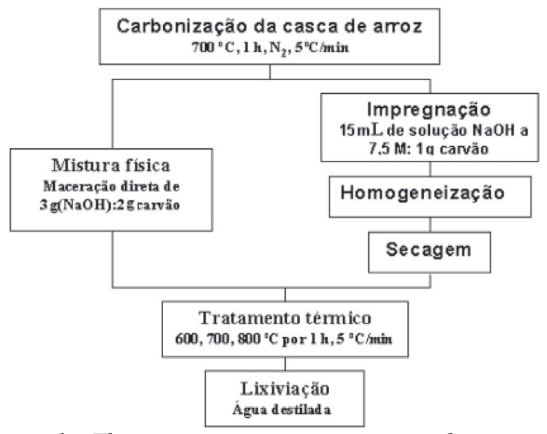

Figura 1. Fluxograma para preparação das amostras PMF e PIA

(Química Nova, v.30, n.7, p.1664, 2007) 


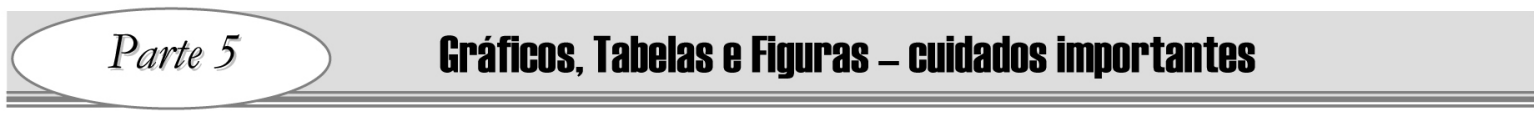

Gráficos, tabelas e figuras são elementos presentes na maioria dos textos científicos, principalmente na seção Resultados. Tais elementos permitem que o leitor tome conhecimento dos dados obtidos de forma rápida e concisa.

Na seção Resultados de um relatório de laboratório de ensino é recomendável que os dados obtidos no experimento também sejam apresentados na forma de tabelas, gráficos ou figuras. Contudo a apresentação de tais elementos requer alguns cuidados, tais como:

- Os gráficos, tabelas ou figuras presentes no trabalho devem ser citados no corpo do texto.

- As tabelas devem ser numeradas em ordem sequencial, em algarismos arábicos, e de forma independente da numeração dos gráficos ou figuras.

- Devem ser apresentadas legendas explicativas sobre o conteúdo expresso em cada um dos elementos. As legendas devem ser colocadas acima das tabelas e abaixo das figuras (incluindo os gráficos).

- As unidades utilizadas nos gráficos (eixos $x$ e y) ou tabelas devem ser indicadas. O significado das abreviaturas utilizadas deve ser explicado em notas de rodapé ou na própria legenda.

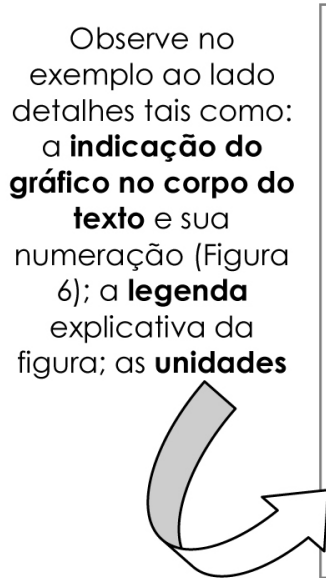

A Figura 6 mostra as isotermas de adsorção de $\mathrm{N}_{2}$ a $77 \mathrm{~K}$ para duas amostras PMF, uma proveniente do precursor rico em sílica [...]

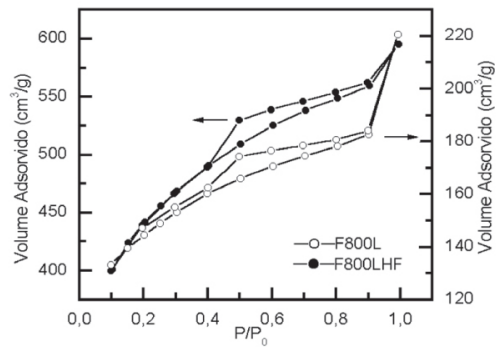

Figura 6. Isotermas de adsorção-dessorção de $N_{2}$ a $77 \mathrm{~K}$. Comparação entre a amostra preparada a partir do precursor rico em sílica ( $F 800 L)$ e a amostra preparada a partir do precursor-HF (F800LHF)

(Química Nova, v.30, n.7, p.1667, 2007)

Nesse exemplo de tabela, observe: a indicação da tabela no corpo do texto e sua numeração (Tabela 4); a legenda explicativa da tabela com significado de abreviatura (ASE); indicação das unidades.

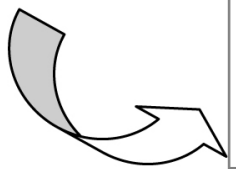

Os resultados de análise da estrutura porosa das amostras ativadas em comparação com o precursor, mostrados na Tabela 4 , indicam que o processo de ativação levou de fato ao aumento da porosidade das amostras ativadas e lavadas, com um comportamento crescente da ASE com a elevação da temperatura de tratamento térmico.

Tabela 4. Parâmetros obtidos pela análise da estrutura porosa de algumas amostras representativas: área superficial específica (ASE), tamanho médio dos poros e volume de microporos.

\begin{tabular}{lccc}
\hline \multicolumn{1}{c}{ Amostras } & $\begin{array}{c}\text { ASE } \\
\left(\mathrm{m}^{2} / \mathrm{g}\right)\end{array}$ & $\begin{array}{c}\text { Tamanho médio } \\
\text { dos poros } \\
(\AA)\end{array}$ & $\begin{array}{c}\text { Volume de } \\
\text { microporos } \\
\left(\mathrm{cm}^{3} / \mathrm{g}\right)\end{array}$ \\
\hline Precursor & 62 & 10,6 & 0,03 \\
Precursor HF & 530 & 16,8 & 0,29 \\
F800L & 450 & 15,6 & 0,24 \\
F800LHF & 1380 & 16,0 & 0,76 \\
\hline
\end{tabular}

(Química Nova, v.30, n.7, p.1667, 2007) 


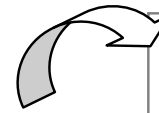

Observe nesse outro exemplo de tabela a legenda explicativa com significado de abreviaturas usadas na tabela; a indicação das unidades; a nota de rodapé com informações adicionais.
Tabela 2. Concentração Inibitória Mínima (CIM), Concentração Bactericida Mínima (CBM) e teores de compostos fenólicos totais e flavonóides do ESP do tipo 6.

\begin{tabular}{|c|c|c|c|c|}
\hline \multirow[t]{2}{*}{ Mês } & CIM & CBM & Fenólicos & Flavonóides \\
\hline & \multicolumn{2}{|c|}{$\mu \mathrm{g} / \mathrm{mL}$} & \multicolumn{2}{|c|}{$\mathrm{mg} / \mathrm{mL}$} \\
\hline Abril & $50-100$ & $>1600$ & $22,26 \pm 0,01$ & $2,48 \pm 0,07$ \\
\hline Maio & $50-100$ & $>1600$ & $22,03 \pm 0,01$ & $2,47 \pm 0,15$ \\
\hline Junho & $100-200$ & $>1600$ & $30,00 \pm 0,00$ & $4,41 \pm 0,02$ \\
\hline Julho & $100-200$ & $>1600$ & $39,38 \pm 0,01$ & $2,5 \pm 0,01$ \\
\hline Setembro & $50-100$ & $>1600$ & $32,16 \pm 0,01$ & $3,72 \pm 0,01$ \\
\hline Outubro & $50-100$ & $>1600$ & $32,13 \pm 0,00$ & $3,67 \pm 0,07$ \\
\hline
\end{tabular}

(Química Nova, v.30, n.7, p.1515, 2007)

Quando os resultados são expostos na forma de imagem (como fotografias) deve-se indicar o aumento realizado para que o leitor possa estimar o tamanho real. Pode ser indicado na própria imagem ou na legenda, como mostra o exemplo abaixo:
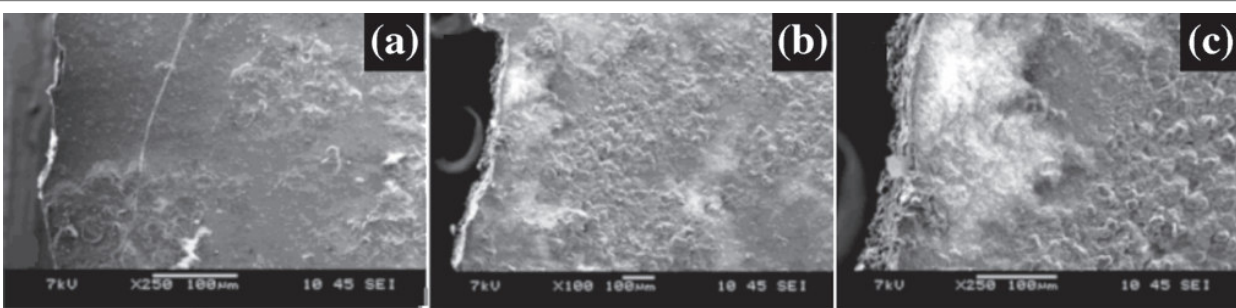

Figura 8. Fotomicrografias da morfologia das fraturas obtidas em ensaios de tração: (a) PHB puro com aumento de 250x; (b) e (c) PHB/Amido com aumento de 100 e $250 x$, respectivamente.

(Química Nova, v.30, n.7, p.1587, 2007)
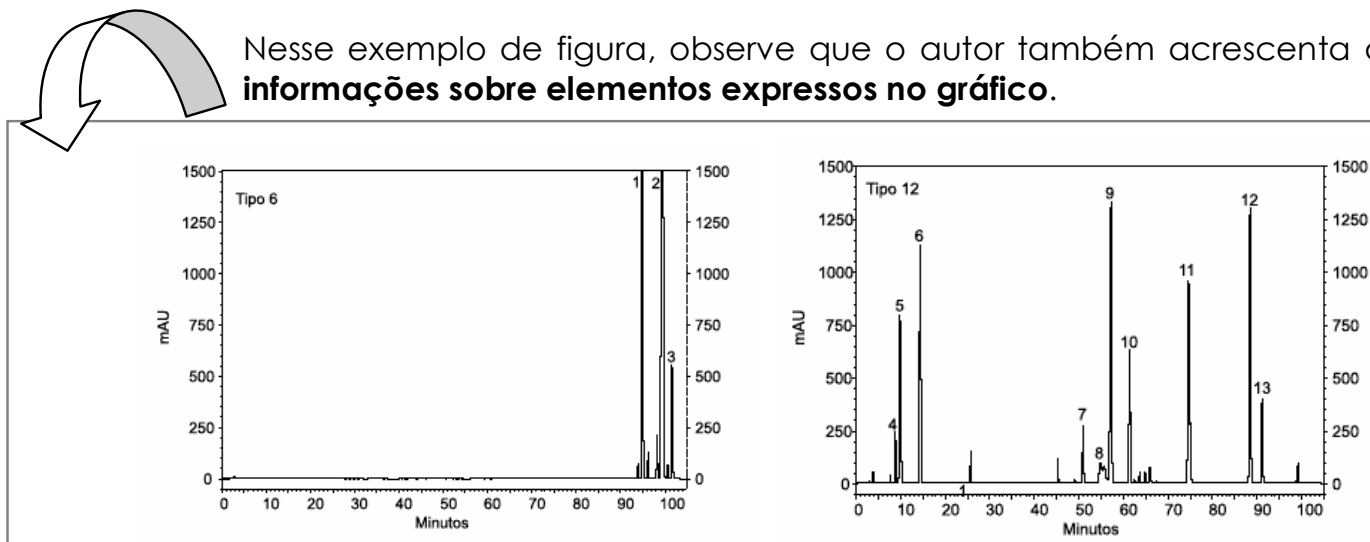

Figura 2. Cromatografia líquida de alta eficiência das própolis tipo 6 e 12 (1, 2, 3, 6, 7, 9, 10, 12 e $13=$ compostos desconhecidos; 4=ácido cumárico; $5=a ́ c i d o$ ferúlico; $8=$ canferide; $12=$ artepillin $C$. 


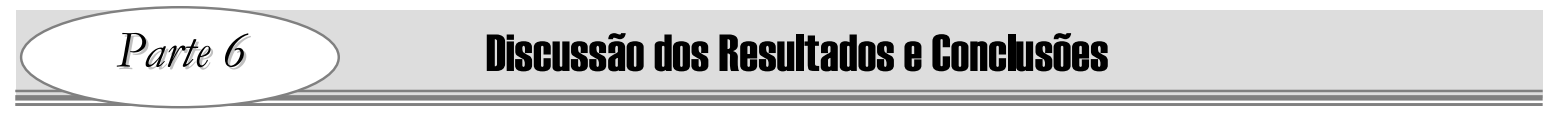

Os resultados e a discussão de um trabalho em geral aparecem em uma única seção, denominada Resultados e Discussão, ou em duas seções distintas, a primeira Resultados e em seguida a seção Discussão. Assim, é importante conhecer as características de cada uma separadamente.

RESULTADOS

- São descritos apenas os dados obtidos no trabalho, sem interpretações.

- Geralmente são apresentados na forma de gráficos ou tabelas.

DISCUSSÃO

- São apresentadas as interpretações e análises dos resultados obtidos.

- Os resultados obtidos são comparados com outros da literatura e as eventuais diferenças, explicadas.

- Hipóteses sobre resultados novos ou inesperados são levantadas.

- A metodologia utilizada para obtenção dos resultados é avaliada.

- São discutidos parâmetros estatísticos.

Nos exemplos a seguir são apresentados excertos de artigos científicos nos quais os autores apresentam seus resultados (dados) e discussão.

$\begin{array}{ll}\begin{array}{c}\text { Apresentação } \\ \text { de dados } e \\ \text { interpretação }\end{array} & \begin{array}{l}\text { Em relação às curvas térmicas obtidas para amostra de propelente BD-111 (Figura 2) } \\ \text { observa-se uma inclinação acentuada da curva na temperatura entre } 80 \text { a } 150{ }^{\circ} \mathrm{C} \text {. Este } \\ \text { comportamento na faixa inicial do aquecimento pode estar relacionado à volatilização da }\end{array} \\ \begin{array}{l}\text { nitroglicerina, devido a sua alta sensibilidade a temperatura [11]. (Eclética Química, v.32, } \\ \text { n.3, p.47, 2007. Grifo nosso) }\end{array}\end{array}$

Notar ainda que, comparando a Figura 3 e a Figura 4, com o aumento da temperatura de ativação ocorre uma pronunciada redução da intensidade dos picos característicos do $\mathrm{Na}_{2} \mathrm{SiO}_{3}$, sugerindo seu consumo pela reação deste com o $\mathrm{Na}_{2} \mathrm{CO}_{3}$, levando à formação de novos produtos que, provavelmente, estão distribuídos desordenadamente na matriz carbonosa. Estas informações concordam com as medidas de $\mathrm{RMN}$ de $29 \mathrm{Si}^{34,35}$ realizadas, sugerindo que para temperaturas elevadas ocorre a decomposição do $\mathrm{Na}_{2} \mathrm{SiO}_{3}$. (Química Nova, v.30, n.7, p.1666, 2007)

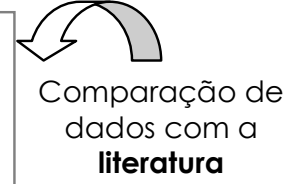

literatura

\begin{tabular}{|c|c|}
\hline $\begin{array}{l}\text { São } \\
\text { levantadas } \\
\text { hipóteses } \\
\text { sobre dados } \\
\text { diferentes dos } \\
\text { relatados na } \\
\text { literatura }\end{array}$ & $\begin{array}{l}\text { Entretanto, o óleo de folhas e frutos analisado neste trabalho apresentou } \\
\text { diferente, quando comparado com aqueles relatados na literatura }{ }^{16-19} \text {. Essa } \\
\text { explicada pela distribuição geográfica das populações estudadas, que cre } \\
\text { de distintas condições de solo e clima, como também pelo horário de cole } \\
\text { extraído. Por essa razão, os resultados obtidos na análise química do o } \\
\text { planta sugerem que a mesma seja um novo quimiotipo que ocorre n } \\
\text { especificamente na floresta de restinga no litoral sul de Pernambuco. } \\
\text { (Química Nova, v.30, n.4, p.839, 2007. Grifo nosso) }\end{array}$ \\
\hline \multicolumn{2}{|c|}{$\begin{array}{l}\text { O espectro de absorção de UV é um dos parâmetros físico-químicos mais utilizados para } \\
\text { se avaliar própolis }{ }^{33,34} \text {, pois as suas atividades farmacológicas têm sido atribuídas a } \\
\text { compostos fenólicos, tais como flavonóides, ácido caféico, ácido cinâmico e derivados, os } \\
\text { quais absorvem nesta região do ultravioleta. De acordo com a Figura } 1 \text {, pode-se observar } \\
\text { que as própolis dos tipos } 6 \text { e } 12 \text { apresentaram um perfil de absorção totalmente distinto e } \\
\text { com absorbâncias máximas nos comprimentos de onda de } 279 \text { e } 302 \mathrm{~nm} \text {, respectivamente, } \\
\text { faixas de absorção para compostos fenólicos. A absorbância máxima da própolis do tipo } 6 \\
\text { foi também cerca de } 3 \text { vezes menor que a do tipo 12, indicando assim uma menor } \\
\text { concentração de fenólicos. (Química Nova, v.30, n.7, p.1513,2007) }\end{array}$} \\
\hline
\end{tabular}

Entretanto, o óleo de folhas e frutos analisado neste trabalho apresentou um perfil químico diferente, quando comparado com aqueles relatados na literatura ${ }^{16-19}$. Essa diferença pode ser especificamente na floresta de restinga no litoral sul de Pernambuco.

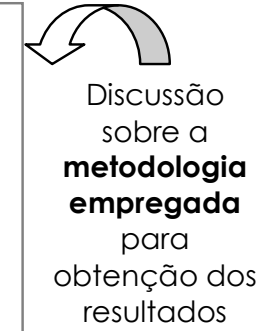

O espectro de absorção de UV é um dos parâmetros físico-químicos mais utilizados para se avaliar própolis ${ }^{33,34}$, pois as suas atividades farmacológicas têm sido atribuídas a compostos fenólicos, tais como flavonóides, ácido caféico, ácido cinâmico e derivados, os quais absorvem nesta região do ultravioleta. De acordo com a Figura 1, pode-se observar que as propolis dos tipos 6 e 12 apresentaram um perfil de absorcão totalmente distinto e faixas de absorção para compostos fenólicos. A absorbância máxima da própolis do tipo 6 concentração de fenólicos. (Química Nova, v.30, n.7, p.1513, 2007) 


\begin{tabular}{|c|c|}
\hline $\begin{array}{l}\text { Discussão } \\
\text { sobre análise } \\
\text { estatística dos } \\
\text { dados }\end{array}$ & $\begin{array}{l}\text { Embora os resultados apresentados na Figura } 7 \text { demonstraram haver variações na hidratação } \\
\text { das amostras dos filmes testados, após análise estatística (ANOVA) apenas as composições } \\
90: 10 \text { e 80:20 contendo sulfato de condroitina natural apresentaram valores significativos } \\
\text { (p<0,05) quando comparados com a amostra do controle (100\% Eudragit@ RS } 30 \text { D). } \\
\text { (Química Nova, v. } 30, \text { n.2, p.316, 2007. Grifo nosso) }\end{array}$ \\
\hline
\end{tabular}

Na seção Conclusão, como diz o próprio nome, apenas as principais conclusões do trabalho são descritas resumidamente. Portanto, não se deve apresentar novamente todos os dados obtidos ou citar dados ou conclusões de outros autores. Também nesta seção podem ser sugeridas aplicações ou ainda indicações de trabalhos futuros. Observe a seguir alguns exemplos de Conclusão.

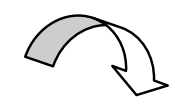

\section{Apresentação das principais conclusões do trabalho}

As propriedades mecânicas e morfológicas do PHB e PHB-HV bem como suas blendas com $20 \%$ de amido foram avaliadas antes da biodegradação. Pode-se afirmar que houve uma diminuição nas propriedades mecânicas dos poliésteres com a incorporação do amido. [...]

A alteração da estrutura química do polímero pela presença de grupos característicos da degradação dos poliésteres foi confirmada pela espectroscopia de RMN $\left({ }^{1} \mathrm{H}\right)$ e infravermelho após o ensaio de degradação.

(Química Nova, v.30, n.7, p.1587, 2007.)

A obtenção do núcleo 5,6-metilenodioxindol (VI) via ciclização redutiva do $o, \beta$-dinitroestireno foi conduzida conforme procedimento da literatura. Este empregou piperonal como material de partida, fornecendo o produto desejado em 3 etapas com rendimento global de $46 \%$. [...]

As substâncias sintetizadas foram caracterizadas por análises no IV, $\mathrm{RMN}{ }^{1} \mathrm{H} \mathrm{e}^{13} \mathrm{C}$, espectrometria de massa, análise elementar e ponto de fusão, apresentando dados compatíveis com as estruturas propostas.

Os ensaios conduzidos com o ácido 5,6-metilenodioxindol-3-il-metanóico (IX) para a avaliação da atividade reguladora de crescimento vegetal quanto a promoção de crescimento de radículas em sementes germinadas de Lactuca sativa, Cucumbis sativus e Raphanus sativus não foram muito expressivos, pois as médias dos tamanhos das raízes ficaram muito próximas entre si nas várias concentrações não apresentando diferença estatística significativa. (Química Nova, v.30, n.4, p.767, 2007.)

\section{Apresentação de possíveis aplicações}

Os filmes na composição 90:10 com sulfato de condroitina modificado demonstraram índice de hidratação, permeabilidade e propriedades morfológicas com potencial de aplicação como um insumo no desenvolvimento de novossistemas para a liberação modificada de fármacos.

(Química Nova, v.30, n.2, p.316, 2007. Grifo nosso) 